\title{
Entrevista
}

\author{
Prof. Dr. José Pinhata Otoch
}

\section{Participação no Departamento Científico na Década de 70}

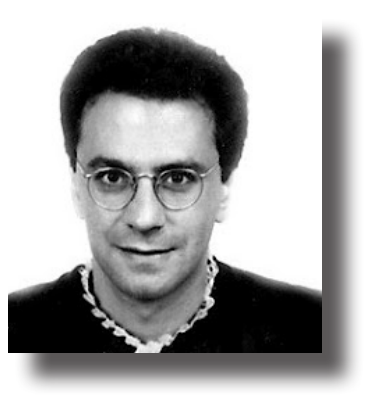

\section{RM: Por que o Senhor decidiu cursar medicina? Sente-se realizado com a profissão?}

JP: A decisão de cursar Medicina foi feita após eu ter cursado um ano de matemática, na USP, e ficar desconfortável com a possibilidade de ter uma profissão na qual não havia interação com as pessoas e com a sociedade de uma forma mais ampla.

\section{RM: Como era a grade curricular da FMUSP da sua época?}

JP: Fui do primeiro ano do curso da fusão (1976), ou seja, a união das duas turmas anteriores - a do curso tradicional com a do curso experimental. Não entendíamos muito bem, no primeiro ano, o que era um currículo médico, mas esta discussão era bastante difundida entre os alunos naquela época. Havia um grande interesse de debater a questão da importância do currículo na formação do médico e qual as características do médico que seriam necessárias para a sociedade. As grandes áreas (clínica médica, cirúrgica, pediatria e ginecologia e obstetrícia) ainda tinham uma influência muito grande no mercado de trabalho e as especialidades começavam a ter presença na Faculdade de Medicina e na vida profissional dos médicos. Vivíamos o começo de uma nova era na qual a incorporação tecnológica iria mudar em muito a atividade médica. Os métodos diagnósticos começavam a ser e ter um novo espaço na medicina e abriam novas possibilidades dentro da nossa escola.
A discussão sobre as mudanças curriculares era intensa e havia assembléias de alunos para decidir as posições do corpo discente em relação às alterações propostas pela comissão de ensino. No final de meu primeiro ano houve uma greve de alunos devido a proposta de mudança curricular no internato, que não foi aceita pelo corpo discente. Ficamos um longo tempo em greve, o que resultou na reprovação de alguns alunos por faltas.

O que me marcou muito nos primeiros dois anos foi a total falta de sincronia entre o curso básico realizado em sua totalidade no Campus da Cidade Universitária e a Faculdade de Medicina com seu hospital distantes no bairro Cerqueira César. Como todas as atividades curriculares eram na Cidade Universitária e o nosso vínculo com a FMUSP era o CAOC e a Atlética.

No $3^{\circ}$ e $4^{\circ}$ anos toda a parte clínica era realizada no Hospital das Clínicas e tínhamos algumas atividades no Centro de Saúde Escola do Butantã, que sempre era lembrado como um resquício do curso experimental. Parecia-me que o curso experimental estava mais focado na interação entre o meio e o homem com uma visão menos organicista do processo de desenvolvimento das doenças, sempre salientando a interação das condições de saúde com os fatores econômicos e sociais.

\section{RM: Como os calouros eram recebidos?}

JP: Não havia uma programação institucional para

Graduado e especializado em Cirurgia Geral e Torácica pela Faculdade de Medicina pela USP. Foi Diretor Técnico da Divisão de Clínica Cirúrgica do HU de 2001 a 2011. É Professor Livre-docente do Departamento de Cirurgia da USP Responsável pela Disciplina de Técnica Cirúrgica e Cirurgia Experimental. Atualmente, é docente responsável pelos cursos curriculares da Graduação em Medicina de Técnica Cirúrgica ( $5^{\circ}$ ano), Estágio Hospitalar em Cirurgia ( $6^{\circ}$ ano) e atua na área de Cirurgia Geral e Torácica com grande ênfase ao ensino. 
o recebimento dos calouros por parte da faculdade. Esta recepção era feita pelo CAOC e pela Atlética de forma separada, além do trote que era um movimento não coordenado dos veteranos sobre os calouros.

\section{RM: Existia alguma tradição que tenha ficado em sua memória?}

JP: Existiam muitas tradições na FMUSP, onde a vida acadêmica era bastante intensa tanto na Atlética como no CAOC. Preciso lembrar que o país vivia uma situação de restrição às liberdades democráticas com uma política ostensiva de repreensão aos movimentos sociais, que sempre eram tachados como subversivos ou comunistas independentes de suas características próprias.

Havia uma motivação especial dos vários setores da vida acadêmica na FMUSP para tentar atrair o calouro para sua posterior "captação ou cooptação". Por exemplo, como calouros, éramos convidados a doar um disco para a discoteca do CAOC que na época tinha um acervo muito grande e fazia parte do Departamento Cultural. Havia o Grupo Teatral Medicina (GTM) e por incrível que pareça onde hoje é o Laboratório de Habilidades existia o Teatro do CAOC, um teatro de arena construído, e mantido à muito custo, pelos próprios alunos.

No CAOC ainda havia outros Departamentos: o Cientifico - responsável pela organização de cursos de extensão universitária e pela Revista de Medicina - e o DPMS, Departamento de Pesquisa Médico Social, do qual saíram grande parte dos integrantes da área de saúde do que depois se constituiria como o Partido dos Trabalhadores.

Com toda a agitação cultural e política da época havia uma discriminação acentuada entre os integrantes do CAOC e da Atlética, sendo os do CAOC sempre identificados com posições políticas de esquerda.

A Atlética reunia um grupo mais heterogêneo e multipartidário, porém sempre com posição política menos expressa, o que não quer dizer não definida. As competições acadêmicas eram bastante importante na vida da faculdade e havia uma grande tradição nos embates entre a Faculdade, a Escola Paulista de Medicina, a Santa Casa e o Mackenzie - SantaPauli-Med e Mac-Med.

O Show Medicina era atuante e crítico, embora houvesse uma tendência em caracterizar seus integrantes com uma posição política mais voltada para a direita, ou sem engajamento na vida política e social do Brasil de então.
RM: Havia muitas extensões para participar? De quais o Sr. participou? Qual se dava o relacionamento entre elas?

JP: As principais extensões estavam relacionadas às ligas - sendo as principais: a liga da sífilis, a liga da doença reumática e a liga de pediatria.

Apesar de ter sido diretor de cursos do DC não participei de nenhuma liga pois as atividades de organização dos cursos ocupavam um tempo bastante grande e associadamente eu ainda participava ativamente da Atlética, embora não estivesse vinculado a nenhum esporte especificamente.

\section{RM: O que levou o Sr. a participar da diretoria do DC nos anos 70?}

JP: Durante o período acadêmico achei importante participar tanto das atividades do CAOC quanto da Atlética. No CAOC como eu não tinha uma posição política partidária definida optei por entrar para o DC, inicialmente como colaborador e posteriormente no segundo ano como diretor de curso.

\section{RM: Como funcionava o DC daquela época? Quais eram as funções do Departamento?}

JP: Os cursos das ligas acadêmicas eram coordenados pelo Departamento Científico que cuidava de toda a parte administrativa e de logística. A Revista de Medicina era de responsabilidade do Departamento que procurava os professores e alunos para divulgação de trabalhos produzidos nas dependências da faculdade ou nos institutos da USP.

\section{RM: Como foi a evolução da RevMed naquela} década? Houve algum momento de dificuldade?

JP: A Revista de Medicina começava a sofrer com a questão da indexação e muitos mandavam parte de seus trabalhos como uma forma de incentivo para a preservação da continuidade do trabalho acadêmico realizado pelo DC. Faltou uma visão mais científica para a preservação dos objetivos iniciais da revista. Esta visão deveria ter o apoio da FMUSP, com a disponibilização de recursos da área da biblioteca, um corpo editorial mais ativo e uma perspectiva de trabalho no sentido de conseguir a indexação da revista. A captação dos trabalhos a serem publicados era feita ativamente pela diretoria e não havia uma política por parte da FMUSP de incentivo a esta atividade. 
RM: As expectativas ao entrar no DC foram atendidas? $\mathrm{O} \mathrm{Sr}$. teria feito alguma coisa diferente naquela diretoria caso fosse possível voltar no tempo?

JP: O momento pelo qual o Brasil passava mudou a forma de atuação acadêmica dos membros do DC. Não havia espaço para atividades na vida acadêmica sem que houvesse um engajamento político. Era o momento da reconstrução da União Nacional dos Estudantes, havia muitas manifestações políticas com greves e passeatas contra a ditadura, todas reprimidas com participação ativa do estado. O país tentava encontrar o estado de direito com a anistia aos que haviam sido exilados, os partidos políticos tentavam se reorganizar saindo da ilegalidade. As atividades ligadas ao aspecto científico da medicina ficaram evidentemente em segundo plano.

\section{RM: Quais os aprendizados principais obtidos ao participar dessa extensão?}

JP: A atuação na vida acadêmica é de importância fundamental para a formação complementar do médico, pois a necessidade de compreensão da sociedade na qual estamos vivendo, seus mecanismos de atuação em relação aos profissionais da saúde e as inter-relações deles decorrentes são base para a inserção do médico na sociedade.
RM: A situação política do Brasil naquela década influenciou de maneira importante o Departamento Científico? Como?

JP: Devido a efervescência política daquela época o DC eram um Departamento com menor expressão dentro do CAOC, sendo as atividades culturais e políticas mais expressivas e de maior interesse por parte dos alunos que participavam do CAOC.

RM: Quais valores do DC e da RevMed o Sr. acha que os membros devem preservar ao longo das gestões?

JP: No momento atual vejo como importante o DC questionar a produção científica realizada no Brasil, a quem ela serve e quais os benefícios para a sociedade. A questão da incorporação tecnológica na área médica com os efeitos diretos na formação médica deve ser o alvo de discussões aprofundadas por parte dos alunos. O médico que a FMUSP forma é o mesmo médico que outras escolas que não possuem os mesmos recursos? Como isto precisa ser visto pela sociedade e pelos órgãos que determinam as regulamentações da profissão.

RM: Para os alunos que estão iniciando agora a vida acadêmica, quais sugestões você daria?

JP: Participem dela, É MUITO CURTA. 